[8] Besekersky V.A. Teoriya system avtomaticheskogo upravleniya. V.A. Besekerskyi. St.Peterburg: Professiya, 2007.

[9] Popov D.N. Dynamyka I regulirovaniye gydro I pnevmosystem. M.: Mashinostroyeniye, 1987.

\title{
СИСТЕМА АВТОМАТИЧЕСКОГО УПРАВЛЕНИЯ БЕСПИЛОТНОГО ЛЕТАТЕЛЬНОГО АППАРАТА
}

\author{
К.О. Габуев ${ }^{1}$, В.О. Гонгало ${ }^{2}$, Н.А. Кучеренко ${ }^{3}$, А.И. Шипко ${ }^{4}$ \\ 1,2,3,4Одесская национальная академия пищевых технологий \\ E-mail: ${ }^{1}$ kostyacart@gmail.com, ${ }^{2}$ skipper12@gmail.com, ${ }^{3}$ tala08@ukr.net, ${ }^{4}$ shipko.arkadiy@gmail.com
}

Copyright $(\mathcal{C} 2017$ by author and the journal "Automation technological and business - processes". This work is licensed under the Creative Commons Attribution International License (CC BY). http://creativecommons.org/licenses/by/4.0/

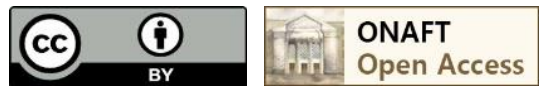

Анотация: В статье рассматривается применение беспилотных летательных аппаратов как в промышленности в иелом, так и в отдельных ее отраслях. Более подробно описывается эксплуатация беспилотных летательных аппаратов в агросекторе. Приведены проблемы, существующие на сегодняшний день в этом секторе, а также методы решения этих проблем при помощи беспилотных технологий. Объяснена важная взаимосвязь между системой автоматического управления и ее интеграцией на беспилотные летательные аппараты. Подробно описывается техническая составляющая дрона, а также взаимосвязь между каждым звеном технического средства автоматизаџии. Приведен пример программного обеспечения, через которое осуществляется управление беспилотным летательным аппаратом.

Abstract: The article deals with the use of unmanned aerial vehicles as in industry in general and as in individual branches. The operation of unmanned aerial vehicles in the agricultural sector is described in more detail. The problems existing for today in this sector, as well as the methods of solving these problems with the help of unmanned technologies are given. The important interrelation between the automatic control system and its integration into unmanned aerial vehicles is explained. Detailed description of the technical component of the drone, as well as the relationship between each link of the technical means of automation. An example of the software through which the unmanned aerial vehicle is controlled is given.

Ключевые слова: робот, дрон, робототехника, автоматизация, система автоматического управления, математическая модель.

Keywords: robot, drone, robotics, automation, automatic control system, mathematical model.

\section{Вступление}

На сегодняшний день технологии по всему миру стремительно развиваются, в том числе и автоматизация, технологический прорыв в индустриализации и в секторах, которые с ней связаны, позволяют смотреть по-новому на существующие проблемы и решать их новыми современными, а также актуальными способами. Например, применение беспилотных технологий в аграрном и промышленном секторах [1] [2] - это одна из новых и очень актуальных технологий, которая еще была недоступна 10 лет назад и только начинала развиваться в то время. Беспилотные технологии настолько универсальны, что могут решать достаточно много проблем в разных отраслях, таких как: сельское хозяйство, добывающая промышленность, геодезия, топография, нефтегазовая промышленность, телекоммуникация, оперативное страхование, энергоэффективность, транспортировка и т.д.

В Украине, как и во всем мире в целом, наиболее активным использованием беспилотных технологий - является аграрный сектор. Внедрение дронов в сельское хозяйство - решает целый ряд проблем, например, таких как: мониторинг сельхоз угодий на наличие подтоплений территории, контроль равномерности посева, прогноз урожайности, борьба с вредителями урожая, распыление удобрений, полив и т.д. Решение всех выше перечисленных 
http://www.atbp.onaft.edu.ua/

проблем, приобрело такой термин, как - точное земледелие. Точное земледелие позволяет эксплуатировать аграрный сектор с максимальной эффективностью для его владельца. При внедрении одного дрона появляется ряд возможностей как: составлении планов и карт сельскохозяйственной земли, мониторинг структуры площадей для посевов и контроль за использованием угодий, определение участков заболоченности местности, эрозии почвы, избытка влаги или засыхания территории, изучение изменений почв и составлении планов и карт изменений почвы, прогнозирование и оценка урожайности и качества плодов, расчет точечного внесения микродоз удобрений и необходимых препаратов, планирование комплекса агротехнологических работ для достижения максимального урожая. Таким образом, «use case» (прикладное применение) дронов - весьма обширно и разнообразно.

Можно сделать вывод, что беспилотные технологии - неотъемлемая часть технологического прорыва в промышленности и конкретно в области автоматизации. Использование дронов без систем автоматизации - давало бы меньший прирост эффективности в используемых отраслях, т.к. ручное управление сразу подразумевает под собой ошибки, связанные с человеческим фактором, которые бы вели к снижению эффективности у поставленных задач. Поэтому при применении дронов можно провести взаимосвязь между эффективностью дрона, т.е. его значимости и его системой автоматизации. Чем система автоматизации качественнее, стабильнее и точнее, тем становится больше эффективность от использования дрона.

На сегодняшний день, по миру существует много различных разработок систем автоматического управления дронами, причем как самолетного типа, так и мультироторного. Системы автоматического управления дронами - в основном нацелены на автоматический полет по конкретному маршруту и на стабилизацию в пространстве. Под стабилизацией в пространстве подразумевается управление положением беспилотного летательного аппарата относительного пространственных углов тангажа, крена и рысканья. В литературе они могут встречаться как углы Крылова или углы Эйлера. Автоматический полет по маршруту - в свою очередь подразумевает позиционирование или же преодоление конкретной точки в пространстве с координатами $\mathrm{x}, \mathrm{y}, \mathrm{z}$, или точку с конкретным значением широты, долготы и высоты. Системы автоматического управления (САУ) беспилотными летательными аппаратами (БПЛА) принципиально делятся на 2 категории - БПЛА мультироторного типа (квадрокоптеры, октокоптеры, трикоптеры и т.д.) и БПЛА с фиксированным крылом, т.е. самолётного типа. Как правило, САУ БПЛА в большинстве случаев адаптивные, имеют несколько внутренних перекрестных связей и в них положен принцип регулирования по углу, угловой скорости, а также угловому ускорению.

В Одесской Национальной Академии Пищевых Технологий на кафедре Автоматизации технологических процессов и робототехнических систем, в научно исследовательской лаборатории Мехатроники и робототехники разработана САУ БПЛА типа квадрокоптер [1]. В дипломной работе рассмотрена отдельная часть, связанная с автопилотом по маршруту.

Цель и описания технического процесса

Цель процесса полета по определенному маршруту заключается в четком позиционировании квадрокоптера в пространстве и минимальное отклонение от заданной траектории, то есть позиционирование по пространственным координатам X, Y, Z. Эти координаты руководствуются путем комбинированной изменения скоростей отдельных двигателей.

Для процесса управления полетом дрона по заданной траектории, к управляющим воздействиям целесообразно отнести изменение скорости вращения двигателей (она же есть - изменением тяги двигателей) - и1 ... .4. К контролируемым возмущениям целесообразно отнести вес коптера f2. Все остальные входные воздействия, кроме управляющего действия и контролируемого возмущения fl, отнесем к неконтролируемым возмущениям.

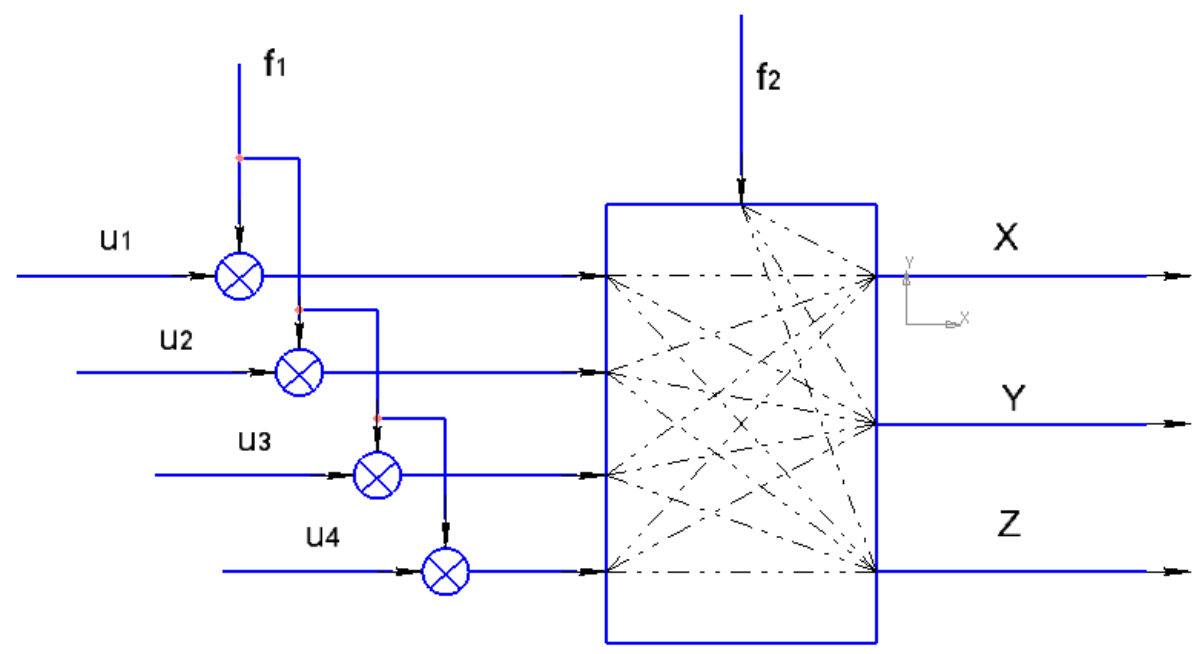

Рис.1 - Структурная схема квадрокоптера как объекта управления 


\section{Описание математической модели} http://www.atbp.onaft.edu.ua/

Математическая модель объекта управления - дроном[3][4], опирается на законы физики. На квадрокоптер действуют такие физические аспекты как, аэродинамика, моменты инерции, крутящий момент, сила притяжения, гироскопический эффект. Ниже приведена таблица с физическими эффектами, которые действуют во время полета дрона. Вращения твердого тела в пространстве можно параметрозуваты, используя несколько методов, таких как углы Эйлера, углы кватернионами и Тейт-Брайана. Дрон движется в пространстве благодаря результирующего вектора направления, в свою очередь зависит от скорости вращения каждого из четырех двигателей. Двигатели, в свою очередь, создают силу тяги и крутящего момента относительно центра масс конструкцию дрона. В аэрокосмической технике оси направлены так же, как для корабля, движущегося в положительном направлении $x$, с правой стороной, соответствующей положительному направлению $y$ и вертикальной стороной, соответствующей положительному направлению $z$. Эти три угла индивидуально называются крен, тангаж и рыскание.
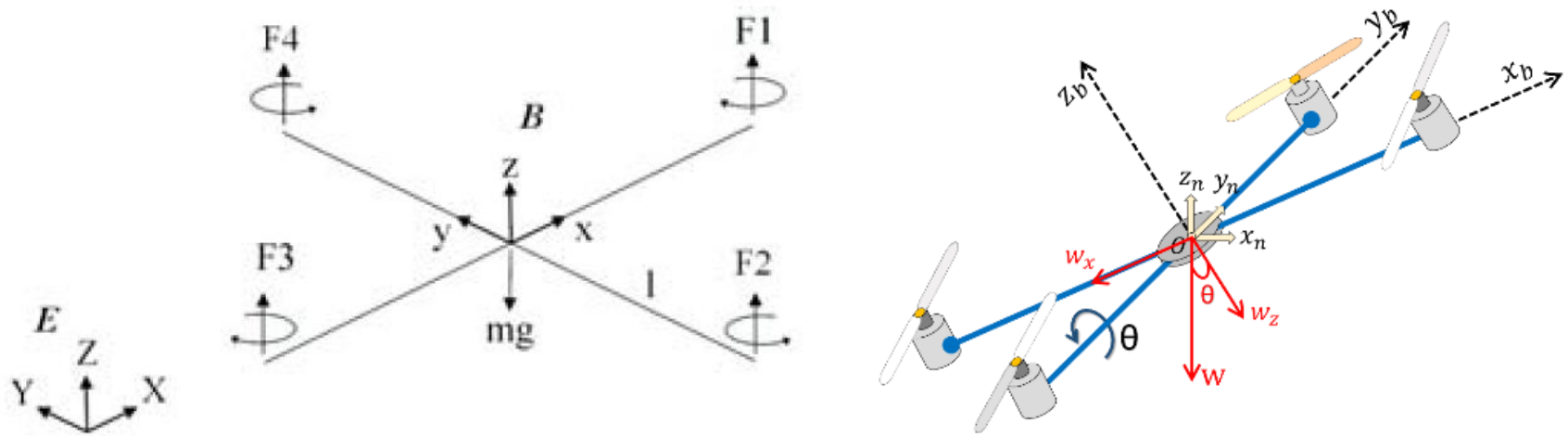

\section{Рис.2 - Силы, воздействующие на квадрокоптер}

На основе законов физики и матриц поворота, были выведены математические зависимости и законы управления, которые стали основой математической модели, собранной в среде Matlab Simulink. Модель включает в себя уравнения движения по пространственным координатам и углам.

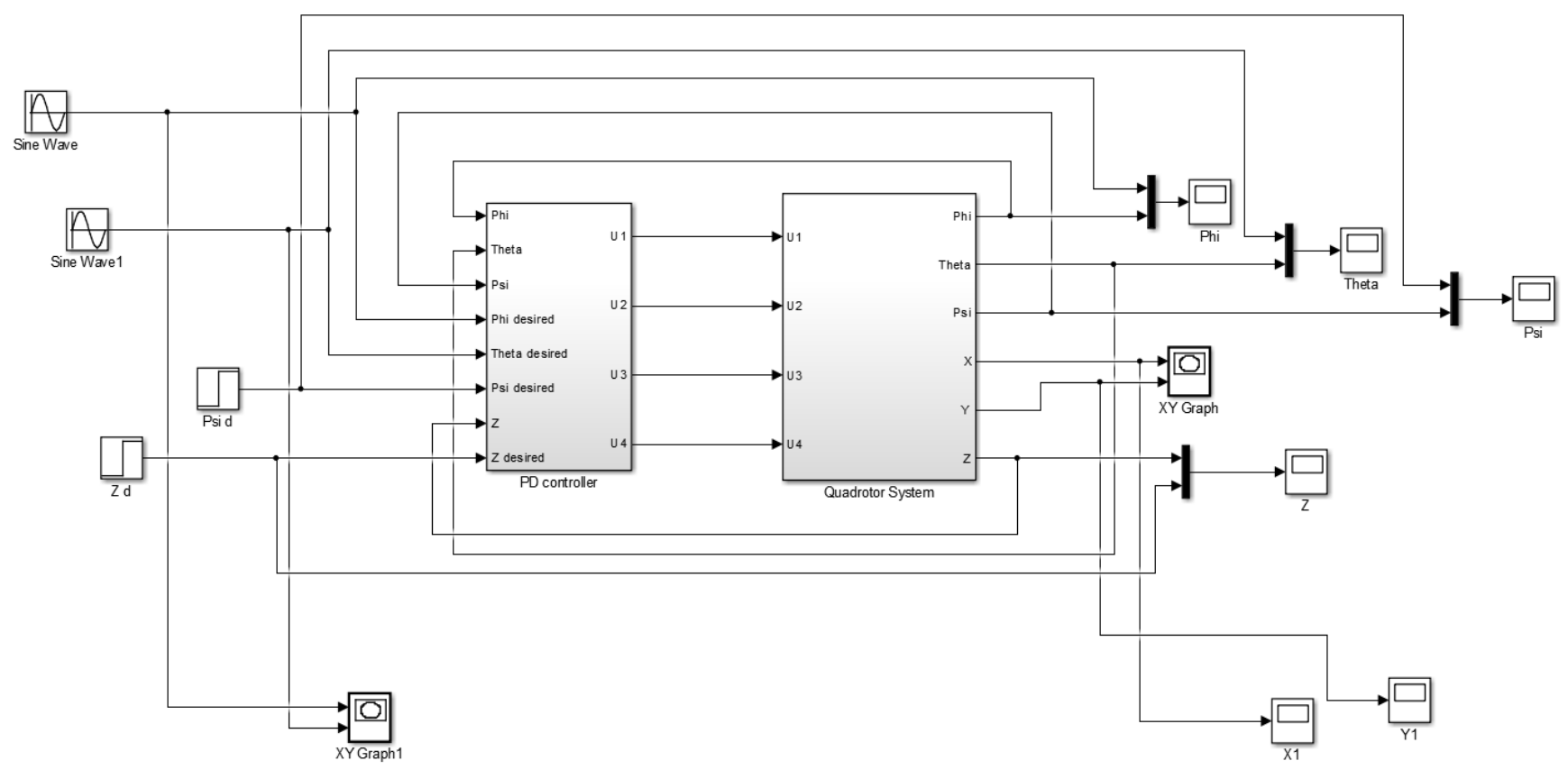

Рис.3 - Математическая модель квадрокоптера, собранная в среде Simulink Matlab

В рамках идентификации математической модели, были проведены ряды активных экспериментов на собранном рабочем прототипе, а также активный эксперимент по получению аэродинамических характеристик воздушных винтов. В результате проведения эксперимента, были получены аэродинамические характеристики воздушных винтов (пропеллеров).Эксперимент проводился на разных частотах вращения до $8000 \mathrm{rpm}$ и с изменением угла атаки винта до 40 град. Испытания проходили в Харьковском аэрокосмическом университете, на кафедре аэрогидродинамики. 


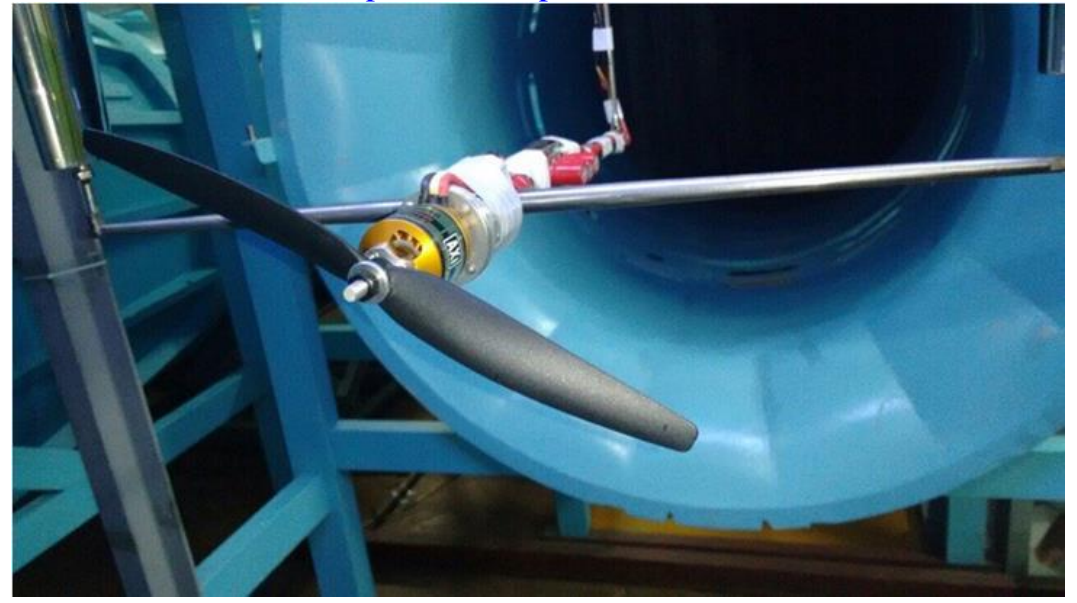

\section{Рис.4 - Эксперимент для получения аэродинамических свойст воздушных винтов}

Описание технической базы

Рабочий прототип квадрокоптера, собирался на базе полётного контроллера Рixhawk, бесколлекторных электродвигателях постоянного тока, GPS навигатора, комплекта радиотелеметрии и контроллеров скорости оборотов двигателей.

Полетный контроллер включает встроенный гироскоп, акселерометр, компас и барометр. В качестве полетного контроллера на борту дрона использоваться такой контроллер как Pixhawk. Pixhawk это новая продвинутая система автопилота построена на базе проекта с открытыми исходными данными PX4 и произведена компанией 3d Robotics. Среди основных достоинств можно отметить быстрый мощный 32-битный процессор и сенсоры от известной компании ST Microelectronics ${ }^{\circledR}$ и операционная система реального времени NuttX что обеспечивает невероятную производительность, гибкость и надежность при управлении любым автономным устройством. Преимуществами платы Pixhawk есть встроенная многопоточность, Unix / Linux- подобное окружение, полностью новые функции автопилота, такие как Lua- скриптинг для миссий и поведения в полете, уровень драйвера PX4 настраиваемый обеспечивает плотность времени во всех процессах. Основной модуль Рixhawk может быть расширен дополнительными опциями, такими как цифровой датчик воздушной скорости, поддержкой внешних разноцветных светодиодных индикаторов, внешнего компаса и др. Вся периферия автоматически определяется и конфигурируется.

В качестве датчика, который будет давать информацию как о геоположення дрона, так и дополнительно отслеживать его высоту полета выступать - GPS модуль Ublox NEO - M8N с компасом. Этот модуль включает так же компас, поскольку использоваться на Дроне будет непосредственно он. Преимущество внешнего компаса от встроенного в полетном контроллере в том, что вибрации, создаваемые работой двигателей, меньше делать влияния, повышая тем самым точность поддержания направления (курса). GPS модуль Ublox NEO - M8N имеет более высокую точность (до 0.6 метров) по сравнению с предыдущими версиями модуля, а также ниже потребление энергии. Идеально подходит для точных и стабильных полетов по карте на летательных средствах. NEO - M8N отличает быстрый поиск сигнала, высокая точность позиционирования и функциональность. NEO - M8N GPS использует оригинальные чипы M8N. Встроенный компас. Обновления позиционирования улучшено до 10 ГГц. Модуль GPS поддерживает различные спутниковые системы позиционирования, например, европейские, японские, китайские, в том числе и российскую спутниковую навигационную систему ГЛОНАСС. Поддержка такого количества различных спутниковых систем обеспечивает высокую точность позиционирования дрона в пространстве.

Двигатели - один из главных исполнительных механизмов на борту дрона. На дроны и всех БПЛА используются бесколлекторные (безщеточные) трехфазные двигатели постоянного тока. При их подборе следует обратить внимание на их номинал, а именно на количество оборотов в вольт (KV), диаметр статора и ротора в данном случае 2213. Двигатели следует прежде всего подбирать с охлаждением, для того, чтобы они как можно меньше изнашивались (перегревались) и могли стабильнее работать в жаркую погоду, а также подбирать двигатели в зависимости от веса конструкции дрона. При большем весе дрона необходимо подбирать двигатели с меньшим KV и с большим размером винта, тем самым создавая больший крутящий момент, то есть создавая большую тягу для подъема конструкции дрона. Также следует обратить внимание на двигатели именно для мультироторних аппаратов, поскольку различия между этими двигателями и двигателями, предназначенными для самолетных БПЛА.

Регулятор скорости оборотов двигателя. Есть небольшой платой с микроконтроллером, которая при получении сигнала с полетного контроллера (широтно импульсной модуляции) увеличивает или уменьшает количество оборотов у двигателя. Ширина импульса ШИМ меняется в диапозоне 1-2 микросекунд. При 1 микросекунде двигатель выключен, при 1.5 микросекунде двигатель работает на 50\% и при ширине импульса в 2 микро секунде двигатель работает с максимальной мощностью, выдавая максимальное количество оборотов. Регуляторы, как и двигатели, необходимо, подбирать прежде всего под тип дрона, есть существенная разница между регуляторами самолетного типа и мультироторного типа. На мультироторних регуляторах частота работы составляет минимум 600Гц, тогда как 
http://www.atbp.onaft.edu.ua/

на самолетных регуляторах хватает и частоты в 400 Гц. Еще один важный критерий при подборе регулятора это отсутствие встроенного ВЭС (звено исключает батарею), то есть дополнительное питание. При наличии встроенного питания в регуляторе скорости, на вырабатываемые управляющие сигналы с этой платы, идёт наводка дополнительных шумов, приводящих к искажению сигнала управления. При встроенном ВЭС в плату регулятора скорости - рекомендуется использовать ферритовое кольцо, для погашения таких шумов. Так же на мультироторных регуляторах скорости наблюдается большая синхронизация в работе и возможность их калибровки. Кроме перечисленных выше критериев, регуляторы подбираются по пиковому току, который потребляет двигатель.

Описание программного обеспечения

Касательно программного обеспечения, то дроном можно управлять с нескольких программ. Программы по управлению дроном называются «наземными станциями», по скольку управление происходит дистанционно, и на «наземную станцию» приходит информация о состоянии дрона с его борта. Одним из таких ПО является «Qground Control». В данной программе можно проводить наладку и конфигурирование как самого дрона, так и его полётной миссии. Данное ПО является весьма гибким, поскольку поддерживается операционными системами Windows, MacOS, Android, Ios, т.е. есть возможность устанавливать их на такие мобильные устройства, как смартфоны и планшеты.

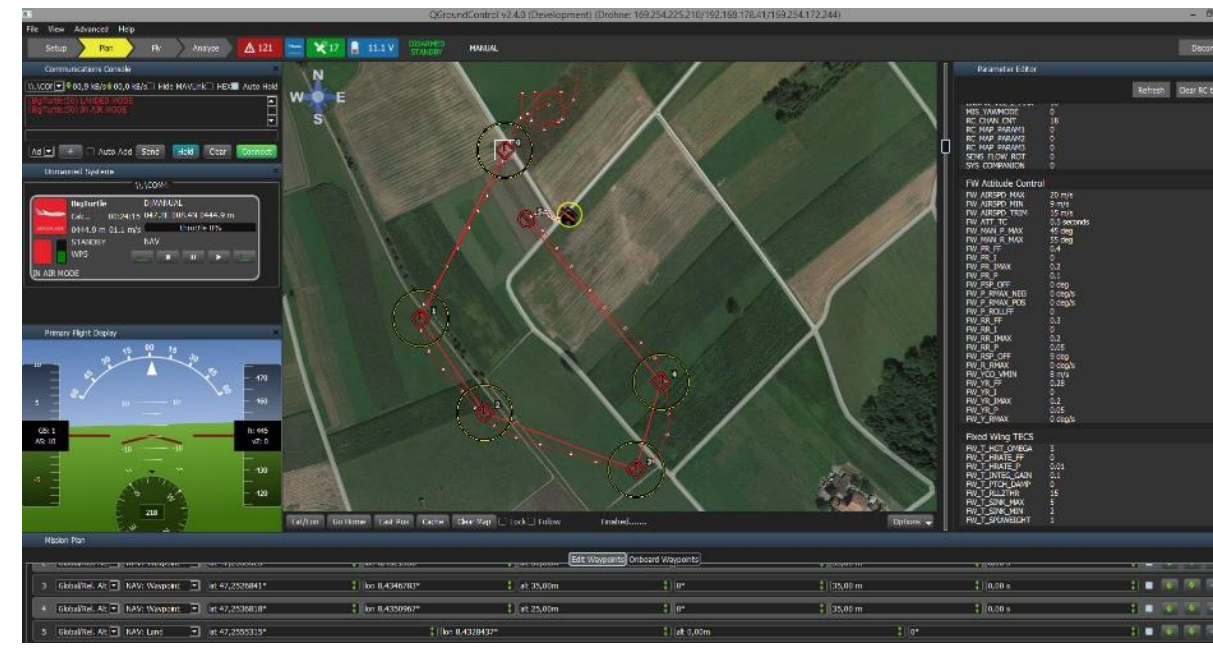

Рис.5 - Скриншот ПО «Qground Control»

Интерфейс этого ПО представляет собой несколько вкладок, по наладке летательного аппарата, а именно выбора его типа (мультиротор или самолетный тип), загрузка прошивки, конфигурирование настроек дрон, а также конфигурирование полётного задания. В главном первоначальном окне - выводится SCADA система, о состоянии основных бортовых датчиков, которые показывают положения дрона относительно горизонта, высоту полёта, направление, уровень заряда батареи, а также качество радиосигнала.

Дальнейшие исследования и разработки

Дальнейшими планами исследований является разработка системы автоматического управления БПЛА типа мотопланнер по заданному маршруту, т.е. создание автопилота на базе дрона самолетного типа. Преимущества самолётных дронов над мультироторными в том, что они могут находиться в небе при хорошем раскладе до 6 часов. Такое достаточно большое время полёта, а также большие площади облёта и скорость полёта позволяют применять дроны в других секторах промышленности. Например, в аграрном секторе или секторе оперативной картографии. Как вариант, рассматривается применение дрона совместно с техническим зрением, для обнаружения бытового мусора в прибрежных акваториях Черного моря Одесского региона.

Относительно САУ, у дронов самолетного типа принципиальное отличие в исполнительных механизмах, которые отвечают за его положение в воздухе. Положение дрона в воздухе зависит от комбинированных углов атаки элеронов и элевонов, а также тяги двигателей.
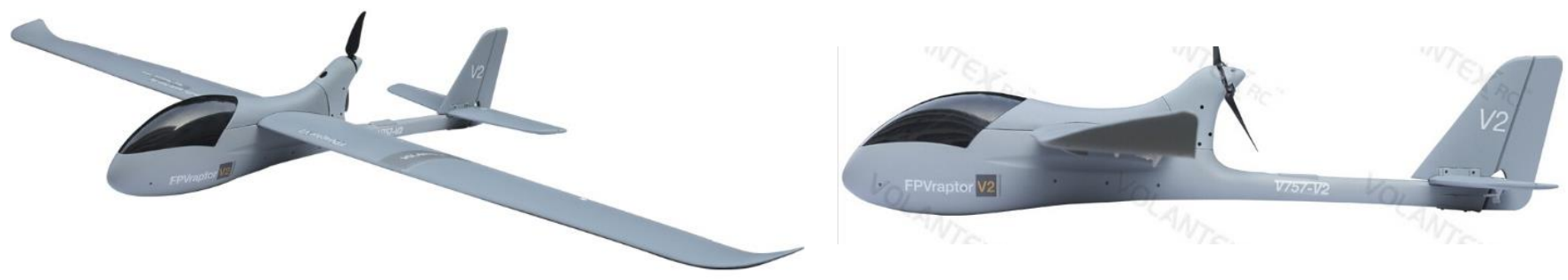

Рис.6 - Изображение модели мотопланнера 
Выводы http://www.atbp.onaft.edu.ua/

Можно подвести итог, что беспилотные летательные аппараты являются неотъемлемой частью робототехники и автоматизации, а по эксплуатации в отраслях промышленности занимают свою нишу. Как факт, на продуктивность и на качество работы БПЛА влияет его система автоматизации, а именно алгоритмы управления и точность контрольноизмерительных приборов. Также, следует обратить внимание на тип БПЛА и сферу его применения.

\title{
Литература
}

[1] Ключникова Н.А. Дроны в агросекторе: способы применения / интернет журнал AgroPortal, 2017.

[2] Ратушняк В.С. Взлет: беспилотные летательные аппараты в сельском хозяйстве / электронный журнал «Агропрактик», 2016.

[3] Богословский С.В., Дорофеев А.Д. Динамика полёта летающих аппаратов, учебное пособие, Санкт-Петербург 2002.

[4] Гурьянов А.Е. Моделирование управления квадрокоптером / электронный научно-техничекий журнал «Инженерный вестник», Россия. МГТУ им. Баумана, 2014.

\section{References}

[1] Kluchnikova N.A. Droni v agrosektore: sposobi primenenia, internet journal AgroPortal, 2017.

[2] Ratushnyak V.S Vzlet: bespilotnie letatel'nie apparativ sel'skom hoziastve, electronic journal Agropractic, 2016.

[3] Bogoslovsky S.V., Dorofeev A.D. Dynamica pol'ota letaiushih apparatov, textbook, St. Petersburg 2002.

[4] Guryanov A.E. Modelirovanie upravleniem quadrocoptera, electronic scientific and technical journal "Engineering Bulletin", Russia. MSTU them. Bauman, 2014.

\section{ИССЛЕДОВАНИЕ ЭФФЕКТИВНОСТИ ФУНКЦИОНИРОВАНИЯ АСОЗ ПТЛ НА МОРСКОМ ЗЕРНОВОМ ТЕРМИНАЛЕ В Г. НИКОЛАЕВЕ}

\author{
И.Н. Кирьязов ${ }^{1}$, С.В. Шестопалов ${ }^{2}$, М.Т. Степанов ${ }^{3}$, В.А. Хобин ${ }^{4}$ \\ ${ }^{1,2}$ SE Group International, Одесса, Украина \\ ${ }^{3,4}$ Одесская национальная академия пищевых технологий, Украина \\ E-mail: ${ }^{1}$ ivan.kiryazov@ se.ua, ${ }^{2}$ stanislav.shestopalov@se.ua, ${ }^{3}$ stepanov197818@gmail.com, ${ }^{4}$ khobin@onaft.edu.ua
}

Copyright (C) 2017 by author and the journal "Automation technological and business - processes".

This work is licensed under the Creative Commons Attribution International License (CC BY).

http://creativecommons.org/licenses/by/4.0/

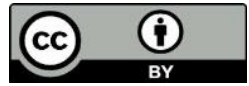

ONAFT

Open Access

Аннотация: В статье рассматриваются результаты фуункционирования в производственньх условиях автоматизиро-ванной системы оптимизации загрузки (АСОЗ) зерном элеватора. Система предназначена для формирования потока зерна одновременно из нескольких источников, повышения производительности, снижения энергоза-трат на перегрузку, предотвращения аварийных ситуаций, связанных с завалами зерна в башмаках норий и надвесовом бункере весов из-за перегрузки. Программное обеспечение системы интегрировано в программное обеспечение автоматизированной системы управления технологическими прочессами элеватора и позволяет оператору задавать компоненты потока отгружаемого зерна и начальной производительности поточнотранспортных линий (ПТЛ), осуществлять выбор режима управления загрузкой ПТЛ и выбор режима задания производительности ПТЛ в текущей технологической ситуачии, контролировать функционирование АСОЗ. Результаты сравнительного анализа эффективности управления загрузкой при погрузке судов оператором «вручную» и с использованием автоматизированной системы оптимизащии загрузки, проведенные в 2016/17 годах, 